\title{
RISIKO KESELAMATAN DAN KESEHATAN KERJA PADA PEKERJA PETERNAKAN SAPI DI PT X CABANG KOTA KEDIRI
}

\author{
Cokorde Dhio Pranamyaditia \\ PT. Nindya Karya General Contractor \\ Jl. Letjen Haryono MT Kav.22, Jakarta 13630 \\ Email: cokordedhio@gmail.com
}

\begin{abstract}
The ranch has many risks, risks that could cause transmission of disease, injury, broken bones, entry of the parasite, up to the dead. In the world of farming in Indonesia is still not pay attention to the job safety for workers. The purpose of this study was to know risk on farm workers PT X branch Kediri. This research was an observational study with cross sectional and descriptive analysis. The data used are primary data from interviews and observations, secondary data derived from the company. The results showed that the hazard identification based on 8 jobs on farms PT X branch in Kediri found 49 hazards. Based on the risk assessment conducted on the 49 hazards can be classified into 36 low risk, 10 medium risk and 3 high risk. Risk control is performed administrative control and use of personal protective equipment. The conclusion of this study 3 high risk was contamination, kicked on cleaning job and kicked on maintenance job. Risk control by PT X lacking in some aspects (attention to the quality of personal protective equipment, the completeness of personal protective equipment workers, and control of sewage cow). Suggestions for improving the quality of livestock is take a concerted gloves and uniforms more appropriate, training on how to handle cattle, how to set up a safe working position, modification of the cage, as well as companies providing the means for individual hygiene.
\end{abstract}

Keywords: Heath and Safety Risk, cattle farm workers, beef cattle

\begin{abstract}
ABSTRAK
Peternakan memiliki banyak risiko, risiko yang ada dapat mengakibatkan tertularnya penyakit, terjadi cedera, patah tulang, masuknya parasit, sampai dengan kematian. Pada dunia peternakan di Indonesia masih belum memperhatikan sisi keamanan kerja bagi pekerjanya. Tujuan dari penelitian ini adalah untuk mengetahui risiko pada pekerja peternakan PT X cabang kota Kediri. Penelitian ini adalah penelitian observasional dengan rancangan cross sectional dan dianalisis secara deskriptif. Data yang digunakan adalah data primer dari hasil wawancara dan observasi, data sekunder yang berasal dari perusahaan. Hasil penelitian menunjukkan bahwa identifikasi bahaya berdasarkan dari 8 pekerjaan pada peternakan PT X cabang Kediri ditemukan 49 bahaya. Berdasarkan penilaian risiko yang dilakukan dari 49 bahaya dapat digolongkan menjadi 36 risiko rendah, 10 risiko sedang dan 3 risiko tinggi. Pengendalian risiko yang dilakukan adalah pengendalian secara administratif dan penggunaan alat pelindung diri. Kesimpulan dari penelitian ini, 3 risiko tinggi yaitu pencemaran, tertendang pada pekerjaan membersihkan dan tertendang pada pekerjaan maintenance. Pengendalian risiko oleh PT X kurang di beberapa aspek (perhatian terhadap kualitas alat pelindung diri, kelengkapan alat pelindung diri pekerja, dan pengendalian limbah kotoran sapi). Saran untuk peternakan adalah memerlukan peningkatan kualitas sarung tangan dan seragam yang lebih sesuai, mengadakan pelatihan mengenai cara menangani sapi, cara mengatur posisi aman bekerja, modifikasi kandang, serta perusahaan menyediakan sarana untuk higiene individu.
\end{abstract}

Kata kunci: Risiko Keselamatan dan Kesehatan Kerja, pekerja peternakan sapi, sapi potong

\section{PENDAHULUAN}

Negara Indonesia adalah negara agraris, masyarakat sangat dekat dengan pertanian dan hewan ternak. Peternakan adalah salah satu yang diminati oleh masyarakat sebagai sumber pemasukan utama maupun sebagai penghasilan tambahan. Peternakan dapat dikategorikan menjadi dua yaitu peternakan pemeliharaan dan pembiakan. Peternakan pemeliharaan adalah menjaga dan merawat ternak bertujuan dipelihara untuk meningkatkan kualitas ternak untuk dijual kembali atau dikonsumsi. Pembiakan disini adalah usaha memperbanyak hewan ternak untuk dijual hasilnya atau dikonsumsi hasilnya (Anonim, 2013).

Menurut situs resmi Dinas peternakan, ternak adalah binatang yang dipelihara untuk dibiakkan dengan tujuan produksi sehingga hewan ternak dapat dibagi menjadi hewan ternak besar dan hewan ternak kecil. Hewan ternak kecil adalah hewan ternak yang berukuran sedang sampai terkecil misalnya adalah 
kambing, babi, kelinci, dan unggas. Sedangkan hewan ternak besar adalah hewan yang diternak dengan ukuran besar dan memiliki berat ratusan kilogram, hewan ternak besar misalnya kerbau, kuda, dan sapi (Anonim, 2013).

Dalam situs resmi Dinas Peternakan Jawa Tengah pada hewan ternak sapi, jenis sapi penggemukan yang sering dipelihara adalah jenis sapi Limousine, Simental, PFH (Peranakan Fries Holstein) jantan maupun peranakan Onggole. Peternakan sapi penggemukan hanya memelihara satu jenis kelamin yaitu sapi jantan, karena sapi jantan cenderung lebih cepat besar dari pada sapi betina yang proporsi lemak lebih tinggi (Anonim, 2013).

Sapi merupakan hewan yang memiliki bobot dewasa dapat mencapai ratusan kilogram, sapi yang sering dipilih untuk penggemukan adalah sapi jantan yang proporsi ototnya lebih banyak dari sapi betina. Keadaan tersebut membuat sapi jantan lebih berbahaya bagi pekerja peternakan, bahaya seperti ini disebut bahaya biologis. Sapi melihat suatu objek dengan warna hitam dan putih saja. Sapi memiliki bidang penglihatan panorama visi, yang berarti mereka dapat melihat segala sesuatu di sekitar mereka kecuali apa yang ada di belakang bagian belakangnya mereka. Jika didekati dari belakang sapi mungkin akan terkejut, sapi memiliki persepsi penglihatan yang terbatas dan buruk dalam mempersepsikan jarak.

Sapi melihat suatu bayangan sebagai lubang, sehingga mereka kadang-kadang takut melewati tempat yang kontras, jadi jalan untuk menurunkan sapi dari kendaraan dan dinding pada jalan yang sempit harus memiliki permukaan datar untuk meminimalkan reaksi ini. Pengurangan pencahayaan yang mengurangi titik yang terang dan jumlah bayangan dapat membantu hewan tenang. Ternak bergerak lebih nyaman dari gelap ke daerah terang daripada sebaliknya. Sapi memiliki postur besar dan kokoh tetapi sapi sebenarnya adalah hewan yang paling mudah panik dari pada hewan lainnya, sapi akan mengawasi dan siaga pada suara maupun orang baru.

Ternak sapi merupakan hewan ruminansia yang melindungi diri dengan kaki belakang. Otot kaki sapi sangat kuat dan memiliki kuku tajam pada ujung kakinya, bila ada sesuatu yang membuatnya panik berada pada jangkauan tendangan maka sapi akan menendang dengan kuat. Kejadian tertendang sapi terjadi pada JP (inisial) warga kabupaten Magetan saat penyembelihan kurban, menurut berita yang ditulis Kartiko (2015) itu menyatakan JP tertendang sampai pingsan. Kejadian tersebut tidak fatal karena tendangan sapi tidak mengenai muka secara telak.

Peternakan PT X yang berada di Kediri merupakan salah satu cabang dari peternakan di Jawa Barat. PT X telah mendirikan cabang di kota Kediri sejak tahun 2012, peternakan PT X merupakan peternakan yang bergerak dalam penggemukan sapi potong (beef cattle) yang telah menerapkan manajemen profesional. Mengenai regulasi pegawai, PT X cabang kediri ditentukan oleh cabang pusat di Jawa Barat yang akan disesuaikan dengan jumlah sapi yang ada. Penggemukan sapi di PT X dapat meningkatkan berat badan hidup sapi antara 1,2 kg sampai dengan $1,3 \mathrm{~kg}$ yang akan digemukkan dalam waktu maksimal 4 bulan. Pemberian pakan pada sapi, PT X menggunakan 30\% pakan hijauan dan $70 \%$ adalah pakan konsentrat. Untuk pakan konsentrat, PT X membuat sendiri dan juga menjual pakan konsentrat tersebut kepada peternak sekitar dengan harga lebih murah dari harga konsentrat pabrikan. Untuk suplai sapi yang akan digemukkan, PT X melakukan import sapi dan juga membeli sapi lokal dari warga maupun dari pasar.

Pekerja peternakan memiliki risiko kecelakaan kerja cukup tinggi, tetapi tidak banyak orang memikirkan keselamatan dan kesehatan mereka. Risiko adalah gambaran ukuran pada kemungkinan bahaya dapat menimbulkan kecelakaan dan ukuran keparahan yang diakibatkan. Semakin besar hewan ternak maka semakin besar tenaga yang dihasilkan saat melakukan perlindungan diri saat panik. Pekerja peternakan memiliki pekerjaan yang memiliki risiko, sapi tidak dapat ditebak apa yang akan dilakukan sapi tersebut saat pekerja berada di dekatnya. Sapi dengan ukurannya yang besar dapat dengan mudah melukai sampai membunuh manusia dengan mudah, tetapi sedikit sekali laporan mengenai kecelakaan di peternakan. Berbanding terbalik dengan fakta, yakni di Peternakan "X", salah satu pekerja mengatakan bahwa tertendang dan tersundul oleh seekor sapi adalah hal yang biasa bagi pekerja peternakan tersebut.

Kecelakaan kerja yang terjadi di industri peternakan tidak mendapatkan perhatian lebih karena jumlah pekerja yang lebih sedikit dari pada industri lain. Beban kerja yang tinggi bagi pekerja peternakan seharusnya menjadi alasan untuk lebih diperhatikan kesehatan dan keselamatan para pekerjanya. Peternakan dapat dibedakan menurut 
jenis hewan yang diternak sehingga membuat bahaya dan risiko memiliki perbedaan. Salah satu hal yang membuat perbedaan bahaya dan risiko pada peternakan adalah ukuran hewan ternak yang memiliki kategori yaitu kecil, sedang, dan besar. Menurut Hutajulu (2008), pendapat dari Michael Maroney yaitu, "Dunia Industri peternakan hampir tidak pernah memikirkan keselamatan kerja, padahal angka kecelakaan bahkan kematian di industri tersebut sangat tinggi dibandingkan dengan industri jenis lainnya."

Menurut penelitian yang dilakukan oleh Yanti (2011), di Kecamatan Tilatang Kamang pada tahun 2010 diperoleh data statistik mengenai persentase kecelakaan sebanyak $64 \%$ merupakan jenis tingkat kecelakaan berat dan 36\% pada tingkat ringan. Kategori kecelakaan dikatakan berat bila terjadinya memar dan luka gores di mana pekerja kehilangan waktu kerja selama 1 jam atau lebih, untuk kecelakaan kategori ringan adalah di mana pekerja mengalami memar yang tidak membuat pekerja kehilangan waktu kerja. Pada survey yang telah dilakukan oleh Yanti (2011), pada 5 peternakan dengan 24 responden didapat angka $41 \%$ responden mengalami kecelakaan.

Penyakit merupakan risiko lain yang dihadapi pekerja peternakan, baik penyakit yang diakibatkan dari singgungan langsung dengan ternak maupun tidak langsung. Menurut artikel yang dibuat oleh Hallman dan Demmin (2007), penyakit (zoonoses) paling sering dihadapi pekerja peternakan adalah Rabies, Brucellosis (Bang's diseases), $Q$ fever, Leptospirosis, Ringworm, Salmonellosis. Menurut Puslitbangnak (Pusat Penelitian dan Pengembangan Peternakan) penyakit yang dapat menular dari sapi pada manusia adalah Anthrax, Rabies, Toxoplasmosis, Scabies, Influenza, dan Brucellosis. Penyakit tersebut memiliki bahaya dan cara penularan yang berbeda, tetapi seluruh penyakit tersebut dapat mengancam jiwa pekerja maupun orang yang bersinggungan dengan ternak yang sakit (Anonim, 2014).

Peternakan X merupakan industri penghasil daging untuk diolah menjadi barang produksi lain maupun dapat diolah menjadi makanan jadi. Pada peternakan ini dilakukan usaha penggemukan sapi, penggemukan sapi disini bertujuan mendapat keuntungan dengan membeli sapi dengan berat badan rendah yang kemudian dijual setelah dilakukan penggemukan beberapa waktu. Peternakan X di kota Kediri merupakan cabang dari peternakan yang berada di Jawa Barat, selain itu masih ada beberapa cabang di kota-kota lainnya di Jawa Timur.

Pekerja pada bagian pengurus sapi memiliki tanggung jawab untuk mengurus 40-60 ekor sapi tiap harinya, banyaknya jumlah sapi yang harus dirawat pekerja membuat tingginya risiko kerja pada pegawai tersebut. Minimnya pekerja memperparah hal tersebut, pekerja bagian kesehatan ternak harus mengerjakan pengurusan sapi saat jumlah sapi yang akan digemukkan banyak tetapi rotasi pekerja dari pusat tidak memberikan tambahan tenaga. Lemahnya manajemen industri peternakan membuat pekerja mendapat kelelahan sehingga meningkatkan risiko untuk terjadinya kecelakaan kerja tiap harinya.

Berdasarkan wawancara dengan pekerja, salah satu kecelakaan kerja pada peternakan ini adalah tertendang oleh sapi yang mengalami kepanikan merupakan kecelakaan paling sering terjadi tiap harinya. Tendangan sapi dengan berat ratusan kilogram dapat mematikan saat mengenai bagian vital tubuh seperti perut yang lunak dan didalamnya ada organ dalam.

Menyadari fakta tersebut maka dilakukan penelitian untuk mengetahui risiko pada pekerja yang bersinggungan langsung dengan ternak di peternakan X kota Kediri (Jawa Timur) sehingga dapat dibuat risk control yang dikomunikasikan pada perusahaan melalui hasil skripsi ini. Tujuan dari penelitian ini adalah mengetahui risiko $\mathrm{K} 3$ pada pekerja peternakan PT X cabang kota Kediri.

\section{METODE}

Jenis penelitian ini adalah penelitian observasional, data yang diperoleh pada penelitian ini adalah data primer dan data sekunder. Data primer didapatkan oleh peneliti melalui observasi yang dilakukan kepada seluruh pekerja yang berhubungan langsung dengan ternak. Observasi dilakukan pada 8 pekerjaan yang ada di peternakan PT X cabang kota Kediri. Data primer juga didapatkan melalui wawancara dengan responden penanggung jawab peternakan. Data hasil observasi menggunakan JSA worksheet diolah secara deskriptif sehingga dapat mendeskripsikan tempat penelitian. Kemudian dilakukan analisa risiko dan evaluasi risiko, setelah evaluasi risiko akan didapatkan hasil penilaian risiko, diterima atau tidak yang dapat dipergunakan untuk penilaian pengendalian risiko. Pengendalian risiko tidak mungkin seluruh risiko dapat dialihkan, sehingga harus dihitung residual risk/risiko sisa. 


\section{HASIL}

\section{Identifikasi Bahaya}

Identifikasi bahaya dilakukan pada 8 pekerjaan yang terdapat pada peternakan PT X, pada pekerjaan tersebut dilakukan observasi dan hasilnya ada pada Tabel 1. Tabel 1 berisi identifikasi bahaya pekerjaan nomer 1 sampai pekerjaan nomer 4, sedangkan Lanjutan Tabel 1 berisi identifikasi bahaya pekerjaan nomer 5 sampai pekerjaan nomer 8 . Pekerjaan nomer 1 sampai nomer 8 secara berurutan adalah memindahkan ternak, mencari rumput, mencacah rumput, mencampur pakan, membersihkan kandang, mengolah kotoran sapi, memeriksa kesehatan sapi, dan maintenance kandang. Pekerjaan tersebut berhubungan langsung dengan ternak sapi, sapi sendiri memiliki bahaya yang berasal dari tanduk, kaki, berat badannya yang bisa mencapai ratusan kilogram dan berbagai penyakit menular.

\section{Penilaian Risiko}

Penilaian risiko yang dilakukan dalam penelitian ini dianalisis secara semi kuantitatif dengan standar dari buku Manajemen Risiko dalam Perspektif K3 OHS Risk Management (Ramli, 2010b), didapat dari penilaian likelihood dan penilaian severity.

Tabel 1. Hasil Identifikasi Bahaya Pekerjaan Nomer 1-4 pada PT X Cabang Kota Kediri

\begin{tabular}{|c|c|c|}
\hline Pekerjaan & Potensi Bahaya & Konsekuensi \\
\hline \multirow{7}{*}{$\begin{array}{l}\text { Memindahkan } \\
\text { ternak }\end{array}$} & Tergelincir/terpeleset & Tergores dan memar \\
\hline & Tertular penyakit & $\begin{array}{l}\text { Anthrax, Brucellois, Leptospirosis, Q fever, Rabies, Salmonellosis, } \\
\text { Toxoplasmosis, Tuberculosis, dan Scabies }\end{array}$ \\
\hline & Terinjak & Memar, retak tulang, dan patah tulang \\
\hline & Terhimpit & Memar, sesak napas, retak tulang, dan patah tulang \\
\hline & Tertanduk & $\begin{array}{l}\text { Memar, tertusuk tanduk, retak tulang, patah tulang, luka dalam, } \\
\text { gegar otak, dan kematian }\end{array}$ \\
\hline & Tertendang & $\begin{array}{l}\text { Memar, pingsan, retak tulang, patah tulang, luka dalam, gegar otak, } \\
\text { dan kematian }\end{array}$ \\
\hline & Tertimpa & $\begin{array}{l}\text { Memar, pingsan, sesak napas, retak tulang, patah tulang, luka } \\
\text { dalam, dan kematian }\end{array}$ \\
\hline \multirow{9}{*}{ Mencari rumput } & Tersayat & Luka sobek, pendarahan, dan tetanus \\
\hline & Tertusuk duri & Luka tusuk, bengkak, dan tetanus \\
\hline & Alergi & Gatal dan kulit merah-merah \\
\hline & Cacing parasit & Kerugian ditimbulkan menurut jenis cacing \\
\hline & Tergelincir/terpeleset & Tergores dan memar \\
\hline & Serangga & Gatal, peradangan, iritasi kulit, dan luka gigitan \\
\hline & Reptile & Luka gigitan, terkena racun, kebutaan, dan kematian \\
\hline & Radiasi matahari & Sun burn, dehidrasi, heat stroke, katarak, dan kanker kulit \\
\hline & Terpotong & Kehilangan bagian tubuh, pendarahan, dan tetanus \\
\hline \multirow{6}{*}{ Mencacah rumput } & Tersayat & Luka sobek, pendarahan, dan tetanus \\
\hline & Alergi & Gatal dan kulit merah-merah \\
\hline & Cacing parasit & Kerugian ditimbulkan menurut jenis cacing \\
\hline & Rumput masuk mata & Iritasi mata, luka pada mata, dan kebutaan \\
\hline & Tersetrum & $\begin{array}{l}\text { Luka bakar, kerusakan otot, kerusakan syaraf, kerusakan jaringan } \\
\text { dan jantung berhenti }\end{array}$ \\
\hline & Terpotong & Kehilangan bagian tubuh, pendarahan, dan tetanus \\
\hline \multirow{5}{*}{ Mencampur pakan } & Tersayat & Luka sobek, pendarahan, dan tetanus \\
\hline & Terkilir & Memar, tulang berpindah posisi, dan otot berpindah posisi \\
\hline & Cacing parasit & Kerugian ditimbulkan menurut jenis cacing \\
\hline & Alergi & Gatal dan kulit merah-merah \\
\hline & Terjepit & Memar, retak tulang, dan patah tulang \\
\hline
\end{tabular}




\section{Lanjutan Tabel 1.}

\begin{tabular}{|c|c|c|}
\hline Pekerjaan & Potensi Bahaya & Konsekuensi \\
\hline \multirow{6}{*}{$\begin{array}{l}\text { Membersihkan } \\
\text { kandang }\end{array}$} & Cacing parasit & Kerugian ditimbulkan menurut jenis cacing \\
\hline & Pencemaran lingkungan & Pencemaran udara, pencemaran air, dan Global warming \\
\hline & Keracunan metana & Pusing, sakit kepala, mual, mengantuk, dan pingsan \\
\hline & Tertular penyakit & $\begin{array}{l}\text { Anthrax, Brucellois, Leptospirosis, Qfever, Rabies, Salmonellosis, } \\
\text { Toxoplasmosis, Tuberculosis, dan Scabies }\end{array}$ \\
\hline & Tergelincir/terpeleset & Tergores dan memar \\
\hline & Tertendang & $\begin{array}{l}\text { Memar, pingsan, retak tulang, patah tulang, luka dalam, gegar otak, } \\
\text { dan kematian }\end{array}$ \\
\hline \multirow{4}{*}{$\begin{array}{l}\text { Mengolah kotoran } \\
\text { sapi }\end{array}$} & Cacing parasit & Kerugian ditimbulkan menurut jenis cacing \\
\hline & Pencemaran lingkungan & Pencemaran udara, pencemaran air, dan Global warming \\
\hline & Keracunan metana & Pusing, sakit kepala, mual, mengantuk, dan pingsan \\
\hline & Tertular penyakit & $\begin{array}{l}\text { Anthrax, Brucellois, Leptospirosis, Q fever, Rabies, Salmonellosis, } \\
\text { Toxoplasmosis, Tuberculosis, dan Scabies }\end{array}$ \\
\hline \multirow{6}{*}{$\begin{array}{l}\text { Memeriksa } \\
\text { kesehatan sapi }\end{array}$} & Cacing parasit & Kerugian ditimbulkan menurut jenis cacing \\
\hline & Terinjak & Memar, retak tulang, dan patah tulang \\
\hline & Tertanduk & $\begin{array}{l}\text { Memar, tertusuk tanduk, retak tulang, patah tulang, luka dalam, } \\
\text { gegar otak, dan kematian }\end{array}$ \\
\hline & Terhimpit & Memar, sesak Napas, retak tulang, dan patah tulang \\
\hline & Tertular penyakit & $\begin{array}{l}\text { Anthrax, Brucellois, Leptospirosis, Qfever, Rabies, Salmonellosis, } \\
\text { Toxoplasmosis, Tuberculosis, dan Scabies }\end{array}$ \\
\hline & Tertendang & $\begin{array}{l}\text { Memar, pingsan, retak tulang, patah tulang, luka dalam, gegar otak, } \\
\text { dan kematian }\end{array}$ \\
\hline \multirow{6}{*}{$\begin{array}{l}\text { Maintenance } \\
\text { kandang }\end{array}$} & Terpalu & Memar, kuku patah, dan retak tulang \\
\hline & Adukan semen & Iritasi kulit, iritasi mata, dan asbestosis \\
\hline & Tertanduk & $\begin{array}{l}\text { Memar, tertusuk tanduk, retak tulang, patah tulang, luka dalam, } \\
\text { gegar otak, dan kematian }\end{array}$ \\
\hline & Terjatuh dari ketinggian & Memar, retak tulang, patah tulang, dan kematian \\
\hline & Tersetrum & $\begin{array}{l}\text { Luka bakar, kerusakan otot, kerusakan saraf, kerusakan jaringan, } \\
\text { dan jantung berhenti }\end{array}$ \\
\hline & Tertendang & $\begin{array}{l}\text { Memar, pingsan, retak tulang, patah tulang, luka dalam, gegar otak, } \\
\text { dan kematian }\end{array}$ \\
\hline
\end{tabular}


Tabel 2. Hasil Penilaian Risiko Pekerjaan Nomer 1-8 pada PT X Cabang Kota Kediri

\begin{tabular}{|c|c|c|c|c|c|c|c|}
\hline \multirow[b]{2}{*}{ Langkah } & \multirow[b]{2}{*}{ Potensi Bahaya } & \multicolumn{3}{|c|}{ Risk Matrix } & \multicolumn{3}{|c|}{ Nilai Risiko } \\
\hline & & $\mathbf{S}$ & $\mathbf{L}$ & $\mathbf{R}$ & 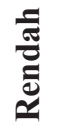 & 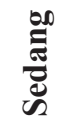 & 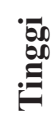 \\
\hline \multirow{7}{*}{ Memindahkan sapi } & Tergelincir/terpeleset & 1 & 2 & 2 & & & \\
\hline & Tertular penyakit & 4 & 1 & 4 & & & \\
\hline & Terinjak & 3 & 3 & 9 & & & \\
\hline & Terhimpit & 3 & 2 & 6 & & & \\
\hline & Tertanduk & 3 & 3 & 9 & & & \\
\hline & Tertendang & 4 & 3 & 12 & & & \\
\hline & Tertimpa & 4 & 3 & 12 & & & \\
\hline \multirow{9}{*}{ Mencari rumput } & Tersayat & 1 & 3 & 3 & & & \\
\hline & Tertusuk duri & 1 & 3 & 3 & & & \\
\hline & Alergi & 1 & 4 & 4 & & & \\
\hline & Cacing parasit & 3 & 2 & 6 & & & \\
\hline & Tergelincir/terpeleset & 1 & 3 & 3 & & & \\
\hline & Serangga & 1 & 3 & 3 & & & \\
\hline & Reptile & 3 & 2 & 6 & & & \\
\hline & Radiasi matahari & 2 & 5 & 10 & & & \\
\hline & Terpotong & 4 & 1 & 4 & & & \\
\hline \multirow{6}{*}{ Mencacah rumput } & Tersayat & 1 & 2 & 2 & & & \\
\hline & Alergi & 1 & 4 & 4 & & & \\
\hline & Cacing parasit & 3 & 2 & 6 & & & \\
\hline & Rumput masuk mata & 3 & 3 & 9 & & & \\
\hline & Tersetrum & 4 & 1 & 4 & & & \\
\hline & Terpotong & 4 & 1 & 4 & & & \\
\hline \multirow{5}{*}{ Mencampur pakan } & Tersayat & 1 & 2 & 2 & & & \\
\hline & Terkilir & 2 & 1 & 2 & & & \\
\hline & Cacing parasit & 3 & 2 & 6 & & & \\
\hline & Alergi & 1 & 4 & 4 & & & \\
\hline & Terjepit & 2 & 1 & 2 & & & \\
\hline \multirow{6}{*}{ Membersihkan kandang } & Cacing parasit & 3 & 2 & 6 & & & \\
\hline & Pencemaran lingkungan & 5 & 5 & 25 & & & \\
\hline & Keracunan metana & 2 & 1 & 2 & & & \\
\hline & Tertular penyakit & 5 & 2 & 10 & & & \\
\hline & Tergelincir/terpeleset & 1 & 2 & 2 & & & \\
\hline & Tertendang & 4 & 4 & 16 & & & \\
\hline \multirow{4}{*}{ Mengolah kotoran sapi } & Cacing parasit & 1 & 2 & 2 & & & \\
\hline & Pencemaran lingkungan & 2 & 1 & 2 & & & \\
\hline & Keracunan metana & 3 & 2 & 6 & & & \\
\hline & Tertular penyakit & 1 & 4 & 4 & & & \\
\hline \multirow{6}{*}{$\begin{array}{l}\text { Memeriksa kesehatan } \\
\text { sapi }\end{array}$} & Cacing parasit & 3 & 2 & 6 & & & \\
\hline & Terinjak & 3 & 3 & 9 & & & \\
\hline & Tertanduk & 3 & 1 & 3 & & & \\
\hline & Terhimpit & 3 & 2 & 6 & & & \\
\hline & Tertular penyakit & 5 & 2 & 10 & & & \\
\hline & Tertendang & 4 & 2 & 8 & & & \\
\hline \multirow{6}{*}{ Maintenance kandang } & Terpalu & 2 & 2 & 4 & & & \\
\hline & Adukan semen & 1 & 3 & 3 & & & \\
\hline & Tertanduk & 3 & 2 & 6 & & & \\
\hline & Terjatuh dari ketinggian & 3 & 2 & 6 & & & \\
\hline & Tersetrum & 4 & 1 & 4 & & & \\
\hline & Tertendang & 4 & 3 & 12 & & & \\
\hline
\end{tabular}




\section{Risiko Sisa}

Risiko sisa adalah hasil dari tingkat risiko dikurangi nilai pengendalian, dipergunakan untuk mengetahui keperluan prioritas pengendalian pada tingkat risiko tinggi. Pengendalian risiko yang telah dilakukan oleh peternakan PT X menurut observasi yang telah dilakukan tercantum pada Tabel 3 .

Tabel 3. Hasil Risiko Sisa Pekerjaan Nomer 1-6 pada PT X Cabang Kota Kediri

\begin{tabular}{|c|c|c|c|c|}
\hline Pekerjaan & Potensi Bahaya & Risk Rating & $\begin{array}{c}\text { Nilai } \\
\text { pengendalian }\end{array}$ & Risiko Sisa \\
\hline \multirow{7}{*}{ Memindahkan sapi } & Tergelincir/terpeleset & 2 & 15 & -13 \\
\hline & Tertular penyakit & 4 & 20 & -16 \\
\hline & Terinjak & 9 & 3 & 6 \\
\hline & Terhimpit & 6 & 3 & 3 \\
\hline & Tertanduk & 9 & 20 & -11 \\
\hline & Tertendang & 12 & 3 & 9 \\
\hline & Tertimpa & 12 & 15 & -3 \\
\hline \multirow{9}{*}{ Mencari rumput } & Tersayat & 3 & 15 & -12 \\
\hline & Tertusuk duri & 3 & 4 & -1 \\
\hline & Alergi & 4 & 16 & -12 \\
\hline & Cacing parasit & 6 & 4 & 2 \\
\hline & Tergelincir/terpeleset & 3 & 4 & -1 \\
\hline & Serangga & 3 & 4 & -1 \\
\hline & Reptile & 6 & 4 & 2 \\
\hline & Radiasi matahari & 10 & 4 & 6 \\
\hline & Terpotong & 4 & 4 & 0 \\
\hline \multirow{6}{*}{ Mencacah rumput } & Tersayat & 3 & 4 & -1 \\
\hline & Alergi & 3 & 16 & -12 \\
\hline & Cacing parasit & 4 & 4 & 0 \\
\hline & Rumput masuk mata & 6 & 4 & 2 \\
\hline & Tersetrum & 3 & 4 & -1 \\
\hline & Terpotong & 3 & 24 & -21 \\
\hline \multirow{5}{*}{ Mencampur pakan } & Tersayat & 2 & 4 & -2 \\
\hline & Terkilir & 2 & 4 & -2 \\
\hline & Cacing parasit & 6 & 4 & 2 \\
\hline & Alergi & 4 & 4 & 0 \\
\hline & Terjepit & 2 & 24 & -22 \\
\hline \multirow{6}{*}{$\begin{array}{l}\text { Membersihkan } \\
\text { kandang }\end{array}$} & Cacing parasit & 6 & 4 & 2 \\
\hline & Pencemaran lingkungan & 25 & 4 & 21 \\
\hline & Keracunan metana & 2 & 4 & -2 \\
\hline & Tertular penyakit & 10 & 4 & 6 \\
\hline & Tergelincir/terpeleset & 2 & 4 & -2 \\
\hline & Tertendang & 16 & 20 & -4 \\
\hline \multirow{4}{*}{ Mengolah kotoran sapi } & Cacing parasit & 2 & 4 & -2 \\
\hline & Pencemaran lingkungan & 2 & 4 & -2 \\
\hline & Keracunan metana & 6 & 4 & 2 \\
\hline & Tertular penyakit & 4 & 4 & 0 \\
\hline
\end{tabular}


Lanjutan Tabel 3. Hasil Risiko Sisa Pekerjaan Nomer 7 dan 8 pada PT X Cabang Kota Kediri

\begin{tabular}{|c|c|c|c|c|}
\hline Pekerjaan & Potensi Bahaya & Risk Rating & $\begin{array}{c}\text { Nilai } \\
\text { pengendalian }\end{array}$ & Risiko Sisa \\
\hline \multirow{6}{*}{$\begin{array}{l}\text { Memeriksa kesehatan } \\
\text { sapi }\end{array}$} & Cacing parasit & 6 & 4 & 2 \\
\hline & Terinjak & 9 & 20 & -11 \\
\hline & Tertanduk & 3 & 15 & -12 \\
\hline & Terhimpit & 6 & 4 & 2 \\
\hline & Tertular penyakit & 10 & 4 & 6 \\
\hline & Tertendang & 8 & 20 & -12 \\
\hline \multirow{6}{*}{ Maintenance kandang } & Terpalu & 4 & 4 & 0 \\
\hline & Adukan semen & 3 & 4 & -1 \\
\hline & Tertanduk & 6 & 15 & -9 \\
\hline & Terjatuh dari ketinggian & 6 & 4 & 2 \\
\hline & Tersetrum & 4 & 4 & 0 \\
\hline & Tertendang & 12 & 20 & -8 \\
\hline
\end{tabular}

\section{PEMBAHASAN}

Identifikasi bahaya di peternakan PT X menggunakan lembar Job Safety Analysis (JSA), pengisian lembar JSA berdasarkan hasil wawancara, data sekunder dan observasi lapangan. Berdasarkan pengisian lembar JSA tersebut, didapat hasil 49 potensi bahaya pada 8 pekerjaan yang berhubungan langsung dengan ternak sapi. Kedelapan pekerjaan tersebut adalah memindahkan ternak, mencari rumput, mencacah rumput, mencampur pakan, membersihkan kandang, mengolah kotoran sapi, memeriksa kesehatan sapi, dan maintenance kandang.

Pada pekerjaan memindahkan ternak sapi ditemukan 7 potensi bahaya yaitu tergelincir/ terpeleset, tertular penyakit, terinjak, terhimpit, tertanduk, tertendang, dan tertimpa. Pekerjaan selanjutnya adalah mencari rumput yang memiliki 9 potensi bahaya yaitu tersayat, tertusuk duri, alergi, cacing parasit, tergelincir/terpeleset, serangga, reptile, radiasi matahari, dan terpotong. Pekerjaan ketiga adalah mencacah rumput, yang memiliki 6 potensi bahaya. Potensi bahaya tersebut adalah tersayat, alergi, cacing parasit, rumput masuk mata, tersetrum, dan terpotong. Pekerjaan keempat adalah mencampur pakan, memiliki potensi bahaya sebanyak 5. Potensi bahaya tersebut adalah tersayat, terkilir, cacing parasit, alergi, dan terjepit.

Pekerjaan kelima, membersihkan kandang memiliki 6 potensi bahaya. Potensi bahaya pekerjaan kelima adalah cacing parasit, pencemaran lingkungan, keracunan metana, tertular penyakit, tergelincir/terpeleset, dan tertendang. Pekerjaan keenam adalah mengolah kotoran sapi dengan 4 potensi bahaya. Potensi bahaya tersebut adalah cacing parasit, pencemaran lingkungan, keracunan metana, dan tertular penyakit. Pekerjaan selanjutnya adalah memeriksa kesehatan sapi yang memiliki 6 potensi bahaya. Potensi bahaya itu adalah cacing parasit, terinjak, tertanduk, terhimpit, tertular penyakit, dan tertendang. Pekerjaan terakhir adalah maintenance kandang dengan 6 potensi bahaya. Potensi bahaya tersebut adalah terpalu, adukan semen, tertanduk, terjatuh dari ketinggian, tersetrum, dan tertendang.

Setelah proses identifikasi bahaya, langkah selanjutnya adalah melakukan penilaian risiko. Penilaian risiko didapat dari hasil perkalian antara $\mathrm{S}$ (severity) dan L (likelihood), hasil perkalian tersebut RR (risk rating) akan dikategorikan dalam 3 kelas yaitu tinggi, sedang, rendah. Likelihood adalah suatu kemungkinan akan risiko untuk terjadi, sedangkan severity merupakan besar suatu efek yang diakibatkan oleh risiko bila terjadi. Hasil penilaian risiko dari Tabel 3 adalah 3 potensi bahaya kategori risiko tinggi, 10 potensi bahaya kategori risiko sedang, dan 36 potensi bahaya kategori risiko rendah.

Pekerjaan pertama adalah memindahkan ternak, memiliki 3 potensi bahaya dengan nilai risiko rendah dan 4 potensi bahaya dengan nilai risiko sedang. Pekerjaan mencari rumput memiliki 8 potensi bahaya dengan nilai risiko rendah dan 1 potensi bahaya yang memiliki nilai risiko sedang. Pekerjaan mencacah rumput memiliki 5 potensi bahaya dengan nilai risiko rendah dan 1 potensi bahaya risiko sedang. 
Pekerjaan keempat adalah mencampur pakan dengan 5 potensi bahaya risiko rendah.

Pekerjaan membersihkan kandang memiliki 3 potensi bahaya risiko rendah, 1 potensi bahaya risiko sedang dan 2 potensi bahaya risiko tinggi. Pekerjaan mengolah kotoran sapi memiliki 4 potensi bahaya dengan risiko rendah. Pekerjaan memeriksa kesehatan sapi memiliki 3 potensi bahaya risiko rendah dan 3 potensi bahaya risiko sedang. Pekerja terakhir adalah maintenance kandang dengan 5 potensi bahaya risiko rendah dan 1 potensi bahaya risiko tinggi.

Pengendalian risiko yang ada di peternakan PT X dilakukan hanya mempergunakan APD (Alat Pelindung Diri) dan tali kekang pada ternak sapi. APD adalah usaha terakhir perusahaan dalam mengurangi atau menghilangkan risiko, maka dari itu pengendalian berupa APD memiliki hubungan dengan kecelakaan kerja (Handayani dkk, 2010). Pengendalian yang ada akan dinilai untuk membuat prioritas pengendalian yang harus dilakukan perusahaan untuk mengurangi bahkan menghilangkan risiko yang ada.

Pada Tabel 3 adalah Tabel penilaian risiko sisa, dari tabel tersebut dapat dilihat hasil tingkat bahaya yang membutuhkan perbaikan pada pengendalian risiko yang dilakukan oleh $\mathrm{PT} \mathrm{X}$. Penilaian risiko sisa didapat dari tingkat risiko dikurangi nilai pengendalian. Hasil dari pengurangan tersebut adalah risiko sisa, untuk kategori $\leq 1$ maka tidak terdapat risiko sisa dan untuk $>1$ terdapat risiko sisa.

Pekerjaan memindahkan ternak terdapat 3 potensi bahaya yang memiliki risiko sisa. Potensi bahaya itu adalah terinjak, terhimpit, dan tertendang. Pekerjaan mencari rumput memiliki 3 potensi bahaya yang masih terdapat risiko sisa. Potensi bahaya tersebut adalah cacing parasit, reptile, dan radiasi matahari. Pekerjaan selanjutnya adalah mencacah rumput yang hanya memiliki 1 potensi bahaya yang memiliki risiko sisa, yaitu rumput masuk mata. Pekerjaan mencampur pakan juga hanya memiliki 1 potensi bahaya yang memiliki risiko sisa, yaitu potensi bahaya cacing parasit.

Pekerjaan membersihkan kandang memiliki 3 potensi bahaya yang masih terdapat risiko sisa. Potensi bahaya tersebut adalah cacing parasit, pencemaran lingkungan, dan tertular penyakit. Pekerjaan mengolah kotoran sapi hanya memiliki 1 potensi bahaya yang masih ada risiko sisa, yaitu potensi bahaya keracunan metana. Pekerjaan selanjutnya adalah memeriksa kesehatan sapi yang memiliki 3 potensi bahaya dengan risiko sisa. Potensi bahaya tersebut adalah cacing parasit, terhimpit, dan tertular penyakit. Pekerjaan terakhir adalah maintenance kandang dengan 1 potensi bahaya yang memiliki risiko sisa, potensi bahaya itu adalah terjatuh dari ketinggian.

Hasil yang didapat dapat menggambarkan efektivitas pengendalian risiko yang telah dilakukan peternakan PT X. Perhitungan yang telah dilakukan penulis masih menghasilkan sejumlah risiko sisa, penyebab risiko sisa adalah pengendalian yang telah dilakukan kurang efektif mengendalikan risiko yang ada. Peran Manajemen K3 dalam pengendalian risiko sangat besar dalam mencegah tingkat keparahan suatu kecelakaan (Endroyono, 2006).

Berdasarkan penilaian risiko sisa dari 49 (empat puluh) potensi sisa yang telah dilakukan pengendalian masih ada 16 risiko yang membutuhkan perbaikan tingkat bahaya. Risiko sisa menunjukkan bahwa pengendalian belum sepenuhnya mengurangi risiko yang ada dan masih ada kemungkinan untuk dapat menimbulkan kecelakaan atau penyakit akibat kerja sehingga perlu adanya upaya perbaikan pengendalian (Ramli, 2010b). Tujuh belas risiko yang membutuhkan perbaikan harus mendapat perhatian lebih dari peternakan agar pekerja tidak menerima kerugian, dari 16 risiko tersebut memerlukan perhatian lebih pada pencemaran lingkungan di pekerjaan membersihkan kandang dan radiasi matahari saat pekerjaan mencari rumput.

Penjabaran hasil diatas menunjukkan bahwa pengendalian risiko penting untuk menghilangkan risiko yang ada, kesadaran perusahaan akan keselamatan dan kesehatan kerja pada pekerjanya perlu ditingkatkan. Keselamatan dan kesehatan kerja sangat berpengaruh pada kinerja, motivasi kerja dan prestasi kerja pegawai sehingga sangat menguntungkan bagi perusahaan (Paramita dan Wijayanto, 2012)

\section{SIMPULAN}

Terdapat 49 risiko kecelakaan pada pekerja peternakan PT X cabang kota Kediri dengan kategori 36 risiko rendah, 10 risiko sedang, dan 3 risiko tinggi. Risiko tinggi terdapat pada pekerjaan membersihkan kandang (2 risiko tinggi) dan maintenance kandang (1 risiko tinggi). Pada pekerjaan membersihkan kandang risiko tinggi pada bahaya tertendang dan bahaya pencemaran lingkungan, sedangkan pada pekerjaan maintenance kandang ada pada bahaya tertendang. Pengendalian 
risiko yang telah dilakukan peternakan PT X cabang kota Kediri kurang.

Hasil penghitungan risiko sisa setelah dilakukan upaya pengendalian masih terdapat 16 potensi bahaya yang membutuhkan perbaikan pada pengendaliannya. Seluruh 16 potensi bahaya tersebut ada pada setiap pekerjaan yang berhubungan langsung dengan ternak sapi.

Risiko tinggi terdapat pada pekerjaan membersihkan kandang yaitu tertendang dan pencemaran lingkungan, sedangkan untuk pekerjaan maintenance kandang adalah tertendang. Risiko pada tiap pekerjaan berbeda walaupun bahaya sama, pada bahaya tertendang memiliki risiko tinggi karena tendangan sapi sendiri sangat kuat.

\section{DAFTAR PUSTAKA}

Anonim. 2013. Jenis Sapi. Dinkeswan. http:// disnakeswan.jatengprov.go.id/blog/category/ jenis-sapi (diakses pada 5 Desember 2014)

Anonim. 2014. Mengenal Beberapa Penyakit Ternak yang Dapat Menular pada Manusia. Puslitbangnak. http://puslitbangnak.blogspot.co.id/2014/05/ mengenal-beberapa-penyakit-ternak-yang. $\mathrm{html}$ ? $=0$ (diakses pada 20 November 2014)

Endroyo, B. 2006. Peranan Manajemen K3 dalam Pencegahan Kecelakaan Kerja Kontruksi. Jurnal. http://puslit2.petra.ac.id/ejournal/index.php/jts/ article/viewFile/16901/16885 (diakses pada 3 Juni 2016)

Eric, H., Demmin, D.M. 2007. Animal Handling Safety. Cornell Agricultural Health and Safety Program. http://www.aphis.usda.gov/emergency_ response/(diakses pada 11 Mei 2015)

Kartiko, R.D. 2015. Ditendang Sapi Kurban, Warga Magetan Masuk UGD. Artikel. http://beritajatim. com/peristiwa/248387/ditendang_sapi_kurban, warga_magetan_masuk_ugd.html (diakses pada 3 Juni 2016)

Paramita, C.C. P dan Wijayanto, A. 2012. Pengaruh Keselamatan dan Kesehatan Kerja terhadap Prestasi Kerja Karyawan pada PT. PLN (Persero) APJ Semarang. Jurnal. Administrasi Bisnis FISIP Universitas Diponegoro. http://ejournal.undip. ac.id/index.php/janis/article/view/4313/3934 (diakses pada 3 Juni 2016)

Pranamyaditia, C.D. Manajemen Risiko Keselamatan dan Kesehatan Kerja pada Pekerja Peternakan Sapi di PT X Cabang Kota Kediri. Skripsi. Fakultas Kesehatan Masyarakat Universitas Airlangga.

Ramli, S. 2010a. Sistem Manajemen Keselamatan \& Kesehatan Kerja OHSAS 18001. Jakarta: PT. Dian Rakyat

Ramli, S. 2010b. Pedoman Praktis Manajemen Risiko dalam Perspektif K3 OHS Risk Management. Jakarta: PT. Dian Rakyat

Handayani dkk. 2010. Fakultas Kesehatan Masyarakat Universitas Ahmad Dahlan Yogyakarta. Jurnal. http://journal.uad.ac.id/index.php/KesMas/ article/download/1092/808 (diakses pada 3 Juni 2016)

Hutajulu, S.R. 2008. Rancangan Perbaikan Sistem Manajemen Keselamatan Kerja Dengan Analisa dan Manajemen Risiko. Tesis. http://lib.ui.ac.id/ file (diakses pada 20 November 2014)

Yanti, K. 2011. Hubungan Perilaku dengan Kecelakaan Kerja pada Pekerja Peternak Ayam Ras di Kecamatan Tilatang Kamang Kabupaten Agam Tahun 2011. Skripsi. http://repository. unand.ac.id/17340/1/SKRIPSI_KHAIRI.pdf (diakses pada 20 November 2014) 